\title{
ASTEMIZOLE, AN INHIBITOR OF ETHER-Ä-GO-GO-1 POTASSIUM CHANNEL, INCREASES THE ACTIVITY OF THE TYROSINE KINASE INHIBITOR GEFITINIB IN BREAST CANCER CELLS
}

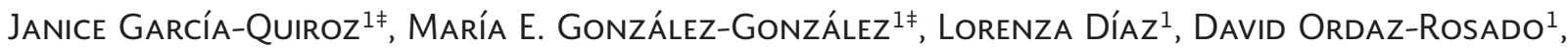 \\ Mariana Segovia-Mendoza ${ }^{1,2}$, Heriberto Prado-García ${ }^{3}$, Fernando Larrea ${ }^{1}$ and Rocío García- \\ BECERRA ${ }^{1,4 *}$
}

Departments of ${ }^{1}$ Reproductive Biology "Dr. Carlos Gual Castro", Instituto Nacional de Ciencias Médicas y Nutrición Salvador Zubirán, Mexico City; ${ }^{2}$ Immunology, Instituto de Investigaciones Biomédicas, Universidad Nacional Autónoma de México, Mexico City; ${ }^{3}$ Chronic Degenerative Diseases, Instituto Nacional de Enfermedades Respiratorias "Ismael Cosío Villegas", Mexico City; and "Breast Cancer Research Program, Department of Molecular Biology and Biotechnology, Instituto de Investigaciones Biomédicas, Universidad Nacional Autónoma de México, Mexico City, Mexico.

‡These authors contributed equally to this work.

\begin{abstract}
Background: Expression and activity of the potassium channel ether-à-go-go-1 (EAG1) are strongly related to carcinogenesis and tumor progression, which can be exploited for therapeutic purposes. EAG1 activity may be reduced by preventing its phosphorylation with epidermal growth factor receptor (EGFR) kinase inhibitors and by astemizole, which blocks the channel pore and downregulates its gene expression. Objective: We aimed to study the potential cooperative antiproliferative effect of the EGFR inhibitor gefitinib and the EAG1-blocker astemizole, in breast cancer cells. Materials and Methods: The cells were characterized by immunocytochemistry. Inhibitory concentrations were determined by non-linear regression analysis using doseresponse curves. The nature of the pharmacological effect was evaluated by the combination index equation while cell cycle analysis was studied by flow cytometry. Results: Astemizole and gefitinib inhibited cell proliferation in a concentration-dependent manner, with inhibitory concentrations (IC 50) values of $1.72 \mu \mathrm{M}$ and $0.51 \mu \mathrm{M}$, respectively. All combinations resulted in a synergistic antiproliferative effect. The combination of astemizole and gefitinib diminished the percentage of cells in $\mathrm{G} 2 / \mathrm{M}$ and $\mathrm{S}$ phases, while increased accumulation in G0/G1 of the cell cycle. Conclusions: Astemizole and gefitinib synergistically inhibited proliferation in breast cancer cells expressing both EGFR and EAG1. Our results suggest that the combined treatment increased cell death by targeting the oncogenic activity of EAG1. (REV INVEST CLIN. 2019;71:186-94)
\end{abstract}

Key words: Breast cancer. Combination index. Epidermal growth factor receptor. Astemizole. Gefitinib.

Corresponding author:

*Rocío García-Becerra

Department of Reproductive Biology

Dr. Carlos Gual Castro

Instituto Nacional de Ciencias Médicas

y Nutrición Salvador Zubirán

Vasco de Quiroga, No. 15

Col. Belisario Domínguez Sección XVI, Del. Tlalpan

C.P. 14080, Mexico City, Mexico

E-mail: rocio.garciab@incmnsz.mx, rocio.garciab@iibiomedicas.unam.mx

Received for publication: 01-10-2018

Approved for publication: 28-11-2018

DOI: $10.24875 / R I C .18002840$ 


\section{INTRODUCTION}

Breast cancer is the most frequently diagnosed neoplasia and a leading cause of cancer death among women ${ }^{1}$. Understanding the foundation of the differential response to treatments based on the molecular signature of the tumor is crucial to stratify patients who may benefit from a targeted therapeutic approach. Among the different phenotypes, the human epidermal growth factor receptor-2 (HER2) positive and the triple-negative breast cancer (TNBC), characterized by the lack of expression of estrogen receptor (ER), progesterone receptor, and HER2, are the most aggressive and clinically challenging tumors $^{2}$. While most of TNBC tumors express the epidermal growth factor receptor 1 (EGFR), the coexpression of HER2 and EGFR worsens the prognosis, giving rise to poorly differentiated tumors with a high metastatic index ${ }^{2}$. Indeed, overexpression of EGFR and/or its ligands is a common trait usually found in multiple cancer types favoring tumor growth, which makes EGFR a useful marker for molecular targeting therapy ${ }^{3,4}$. Therapeutic agents utilized in the clinic for EGFR-positive tumors include small-molecule tyrosine kinase inhibitors (TKIs). Gefitinib, a TKI used as a single agent for EGFR-targeted therapy, has shown to be effective mainly in patients with non-small-cell lung carcinoma-bearing EGFR-activating mutations ${ }^{5}$. Moreover, this TKI inhibits the growth of both human tumor xenografts and breast cancer cell lines expressing different levels of EGFR or HER2 ${ }^{6-8}$. In breast cancer patients, gefitinib is not currently being considered for therapeutic purposes, mainly due to the low response rates for some types of breast tumors $^{9-11}$. Nevertheless, gefitinib treatment has resulted in a significant difference in the complete pathologic response between non-TNBC and TNBC tumors ${ }^{12}$, showing promise in treating this latter type of tumors. Whether tumors will or will not respond to EGFR inhibitors depend on many factors including mutations that drive EGFR hyperactivation, rendering the cell "addicted" to EGFR pathway and, therefore, very sensitive to TKI therapy ${ }^{13}$. On the opposite, cells that are insensitive to TKls may depend on other pathways to survive. Interestingly, one common pathway that drives breast cancer cells proliferation independently of the expression of common molecular markers is the one initiated by the oncogenic potassium channel ether-à-go-go 1 ([EAG1], Kv10.1, KCNH1) ${ }^{14-17}$. EAG1 channels are responsible for the potential membrane hyperpolarization that induces human breast cancer cell progression into the $\mathrm{G} 1$ phase of the cell cycle, resulting in cell proliferation ${ }^{16,18}$. Accordingly, reducing these currents with EAG1 blockers or downregulating EAG1 expression inhibited cell proliferation, an effect that has been observed in ER-positive, HER2-positive, and TNBC cells ${ }^{19-22}$. In general, EAG1 overexpression is a hallmark of cancer ${ }^{23-25}$, particularly in breast tumors (95\% abundance, independently of the molecular signature) ${ }^{25}$. Given that, EAG1 is implicated in carcinogenesis and is a surface-expressed protein; it has been extensively studied as an oncological target due to its accessibility by extracellular pharmacological tools such as astemizole ${ }^{24-26}$.

Astemizole, a non-sedating second-generation $\mathrm{H}_{1}$ histamine receptor antagonist, has shown a significant association with reduced mortality among cancer patients, especially if a concurrent chemotherapy is used ${ }^{27}$. The latter may be explained by the following facts: (1) astemizole inhibits EAG1 currents by binding to open channels from inside the cells ${ }^{28}$; (2) it reduces EAG1 gene expression in breast cancer ${ }^{19,20}$; (3) the blockade of histamine $\mathrm{H}^{1}$ receptors by astemizole decreases histamine-dependent growth of cancer cells ${ }^{26}$; (4) astemizole enhances both lysosomal- and caspase-dependent cell death pathways ${ }^{27}$; and (5) astemizole sensitizes breast cancer cells to chemotherapy while reverts multidrug resistance ${ }^{27}$.

On the other hand, protein tyrosine kinases, particularly EGFR kinase, stimulate EAG1 channel activity by phosphorylating the tyrosine residues Tyr90, Tyr344, and Tyr48529. Therefore, TKls are expected to shutdown EAG1, as shown in HEK293 cells transfected with EAG1 and treated with AG556, a compound that selectively inhibits EGFR autophosphorylation ${ }^{29}$. Indeed, EGFR blocking, at the level of activity and/or expression, significantly reduced EAG1 currents ${ }^{29}$. Consequently, the inhibition of EAG1 accounts in part for the antiproliferative effect of specific EGFR kinase inhibitors.

Based on this background, we investigated the antiproliferative effect of the combination of astemizole with gefitinib, in an effort to decrease both EAG1- and EGFRdependent cell proliferation by maximizing target inhibition. For this study, we chose an ER-positive cell line so that it represents one of the most common tumor phenotypes, but importantly, it also coexpresses EAG1, EGFR, and HER2, all markers of poor prognosis. 


\section{MATERIALS AND METHODS}

\section{Cell culture}

The breast cancer cell line BT-474 was purchased from American Type Culture Collection (ATCC) and maintained in Hybri-Care medium (ATCC) supplemented with $1.5 \mathrm{~g} / \mathrm{L}$ sodium bicarbonate, 100 units/ $\mathrm{mL}$ penicillin plus $100 \mu \mathrm{g} / \mathrm{mL}$ streptomycin, and heatinactivated FBS (all from Invitrogen Life Technologies, NY, USA) to a final concentration of $10 \%$ in humidified atmosphere with $5 \% \mathrm{CO}_{2}$ at $37^{\circ} \mathrm{C}$. All experimental procedures were performed in supplemented HybriCare medium conditioned with $5 \%$ charcoal-strippedheat-inactivated FBS.

\section{Characterization of cells by immunocytochemistry}

Cells were grown on Lab-Tek Chamber Slides (Thermo Scientific) and fixed in $96 \%$ ethanol. Antigen retrieval was achieved by autoclaving in immuno/DNA retriever with EDTA solution (BioSB, CA, USA) during 5 min. Slides were blocked with ImmunoDetector peroxidase blocker (BioSB) for $5 \mathrm{~min}$ and further incubated during 2 h with anti-EAG1 (1:300, Novus Biologicals, CO, USA) or 1 hour with anti-EGFR (1:250, BioSB), antiER $\alpha$ (1:250, BioSB), or anti-HER2 (1:100, Cell Signaling Technology, MA, USA) antibodies. Slides were sequentially incubated with ImmunoDetector BiotinLink and ImmunoDetector HRP label (BioSB) during 10 min each, washed with Tris-buffered saline, stained with diaminobenzidine, and counterstained with hematoxylin.

\section{Cell proliferation and drug combination studies}

Cells were seeded in 96-well plates at a density of 1000 cells per well. After 24 h, cells were incubated in the presence of different concentrations of astemizole (Sigma, St. Louis, MO, USA), gefitinib (kindly provided by AstraZeneca, Mexico City, Mexico), or the vehicle alone (dimethyl sulfoxide, DMSO) during 6 days. Cell proliferation was studied using the colorimetric XTT assay (Roche Applied Sciences, IN, USA) following the manufacturer's instructions. Absorbance was determined at $492 \mathrm{~nm}$ in a Multiskan spectrophotometer (Labsystems Inc., Canada). Furthermore, cell density was determined using the protein-binding dye SRB ${ }^{30}$. The concentrations that caused $20 \%$ and $50 \%$ cell proliferation inhibition (inhibitory concentrations $[I C]_{20}$ and $I C_{50}$, respectively) were calculated by non-linear regression analysis using sigmoidal fitting from the sigmoidal dose-response curve by means of the scientific graphing software Origin (OriginLab Corporation, Northampton, MA). Subsequently, using the $\mathrm{IC}_{20}$ and $I \mathrm{IC}_{50}$ of astemizole and gefitinib, we studied the effect of the drug combination to determine a possible synergism on cell proliferation. Then, combination index $(\mathrm{Cl})$ values were determined applying $\mathrm{Cl}$ equation ${ }^{31}$. For this analysis, an additive effect, synergism, or antagonism were defined as $\mathrm{Cl}$ values $=1.0,<1.0$, and $>1.0$, respectively, as previously reported ${ }^{31}$.

\section{Cell cycle distribution}

BT-474 cells were incubated in the absence or presence of the respective $I C_{50}$ values of astemizole or gefitinib alone or combined during $96 \mathrm{~h}$. After treatment, the cells were collected, washed with phosphate buffer $\mathrm{pH} 7.2$, and fixed in $70 \%$ ethanol $\mathrm{v} / \mathrm{v}$. Then, the samples were washed and incubated in RNAse $(10 \mu \mathrm{g} / \mathrm{ml}), 0.1 \% \mathrm{v} / \mathrm{v}$ Triton $\mathrm{X}-100$, and 7-aminoactinomycin D (7-AAD) (BioLegend, San Diego, CA $)(50 \mu \mathrm{g} / \mathrm{ml})$ solution in the dark at room temperature for $20 \mathrm{~min}$. The DNA content was determined using a FACSCanto II flow cytometer (Becton Dickinson, San Jose, CA, USA). For cell cycle analysis, a total of 30,000 events from 7-AAD area versus 7-AAD wide gate were acquired. Results were analyzed using FlowJo software (LLC, Ashland, OR, USA).

\section{Statistical analysis}

Statistical differences were determined by one-way ANOVA followed by post hoc test Holm-Sidak for pairwise comparisons (SigmaStat 3.5, Jandel Scientific). Differences were considered statistically significant at $p<0.05$.

\section{RESULTS}

\section{Cell characterization}

The cells were characterized by immunocytochemistry to evaluate the expression of the molecular 
Figure 1. Immunocharacterization of breast cancer cells. BT-474 cells showed strong immunoreactivity (brown staining) for estrogen receptor $\alpha$ (ER), ether-à-go-go-1 (EAG1), epidermal growth factor receptor 1 (EGFR), and epidermal growth factor receptor 2 (HER2). Negative control is shown in the inset and was carried out in the absence of primary antibody. Representative images are shown.
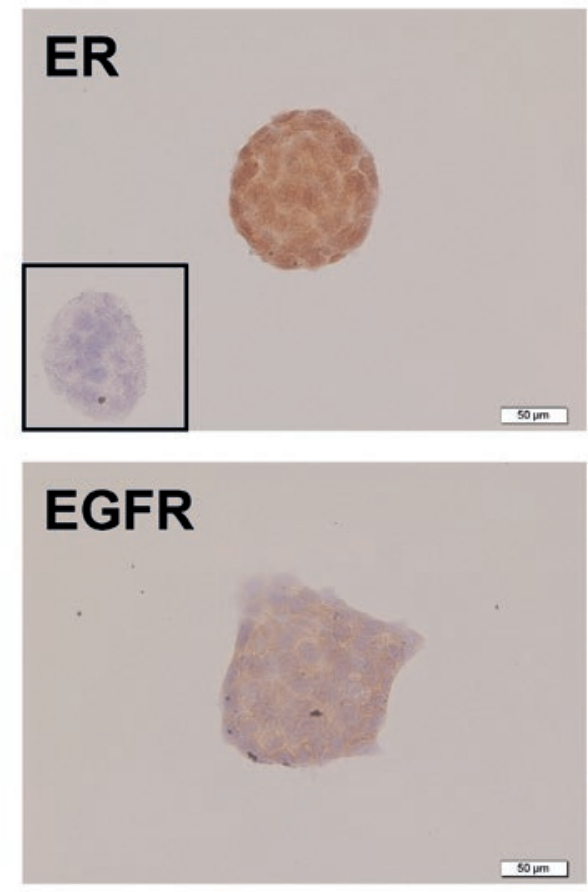

Table 1. IC values for astemizole and gefitinib.

\begin{tabular}{ccc}
\hline IC & $\begin{array}{c}\text { Astemizole } \\
(\mu \mathrm{M})\end{array}$ & $\begin{array}{c}\text { Gefitinib } \\
(\mu \mathrm{M})\end{array}$ \\
\hline 20 & 1.20 & 0.14 \\
50 & 1.72 & 0.51 \\
\hline
\end{tabular}

IC: inhibitory concentrations values of astemizole and gefitinib at 20 and $50 \%$

targets of astemizole and gefitinib. BT-474 cells showed positive immunostaining for EAG1, HER2, and EGFR, which suggest sensitivity to astemizole and gefitinib. In addition, we confirmed ER $\alpha$ presence in BT474 cells (Fig. 1 ).

\section{Antiproliferative effects of astemizole and gefitinib}

To test the functionality of EAG1/HER2/EGFR-targeted treatment, BT- 474 cells were incubated in the presence of increasing concentrations of astemizole or gefitinib. A concentration-dependent antiproliferative
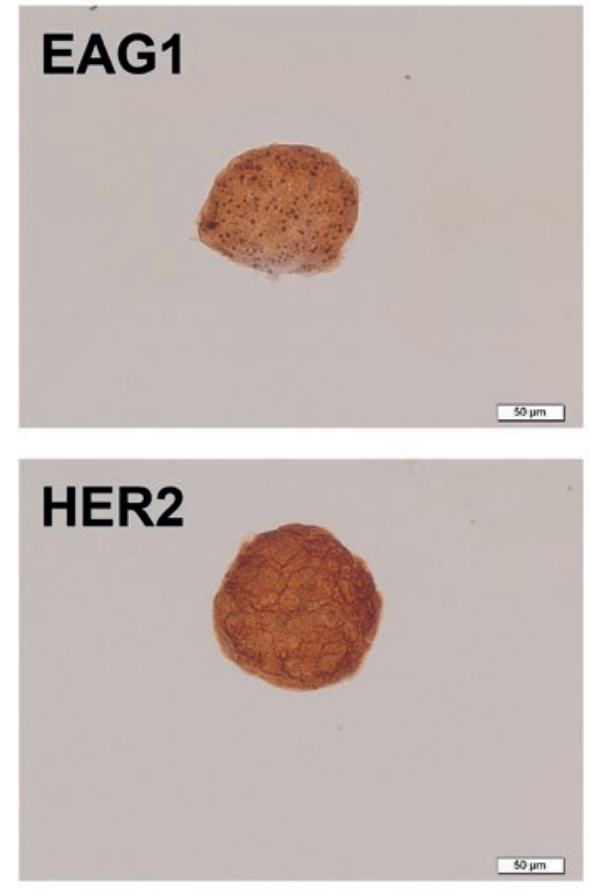

effect of both compounds was observed (Fig. 2), indicating that these cells greatly depended on EAG1/ HER2/EGFR signaling pathways to grow. Based on the range of concentrations tested, we calculated the $\mathrm{IC}_{20}$ and $\mathrm{IC}_{50}$ values for the experimental compounds (Table 1).

\section{Drug combination effects on cell proliferation}

To analyze the potential synergistic antiproliferative effect of astemizole and gefitinib, drug combination studies were carried out using their corresponding $I_{20}$ and $I C_{50}$ values. Results showed that cell proliferation was inhibited in a greater extent when combining the drugs, as compared against each compound alone. Statistical significance was reached using gefitinib at $I C_{20}$ with astemizole at $I C_{50}$ and gefitinib at $\mathrm{IC}_{50}$ in combination with astemizole at both concentrations tested, reaching approximately $80-90 \%$ cell growth inhibition (Fig. 3A). Furthermore, cell density was significantly reduced by the combined treatment compared with non-treated cells (Fig. 3B). 
Figure 2. Astemizole and gefitinib antiproliferative effects on BT-474 cells. The cells were incubated in the presence of increasing concentrations of astemizole (A) or gefitinib (B) during 6 days. Both compounds inhibited cell proliferation in a concentrationdependent manner. Results are depicted as the mean \pm standard deviation of sextuplicate determinations and represent at least five different experiments. Data from vehicle treated cells were set to $100 \%$ and the rest was normalized accordingly. ${ }^{*} \mathrm{p}<$ 0.001 versus control. Proliferation was assayed by measuring the metabolic activity of viable cells by using the XTT colorimetric method.

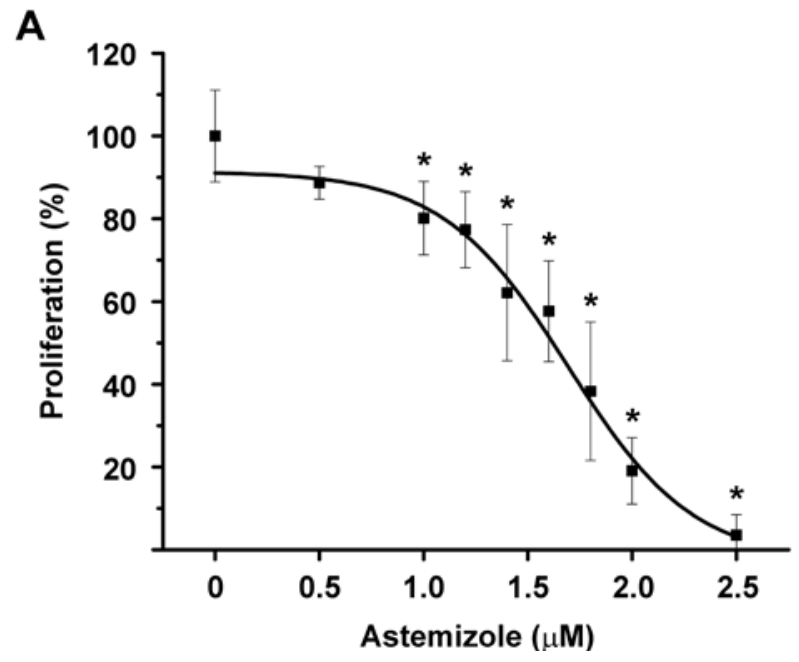

To determine the pharmacological effect that resulted from the drug combinations, $\mathrm{Cl}$ equation was used $^{31}$. A graphic of the fraction affected of cells versus $\mathrm{Cl}$ value for the drug combination is shown in figure 4. All the combination schemes resulted in $\mathrm{Cl}<$ 1 , which reflect synergism in every case. Accordingly, as the concentrations of astemizole and gefitinib increased, the values depicting $\mathrm{Cl}$ ranged from 0.75 to 0.26 , indicating moderate to strong synergism, respectively.

\section{Astemizole combined with gefitinib diminished the percentage of cells in G2/M-phase}

To determine whether the combined treatment modified the cell cycle distribution of BT-474 cells, flow cytometric analysis using a fluorescent marker for DNA was performed. Figure 5 shows the cell cycle profile after treating the cells with astemizole or gefitinib at their corresponding $I C_{50}$ values, alone or combined during 96 hours. As depicted, astemizole and gefitinib per se reduced the percentage of cells in G2/M phase compared to untreated cells. The combination of both drugs further reduced this value, achieving statistical significance when compared with both vehicle- and astemizole-treated

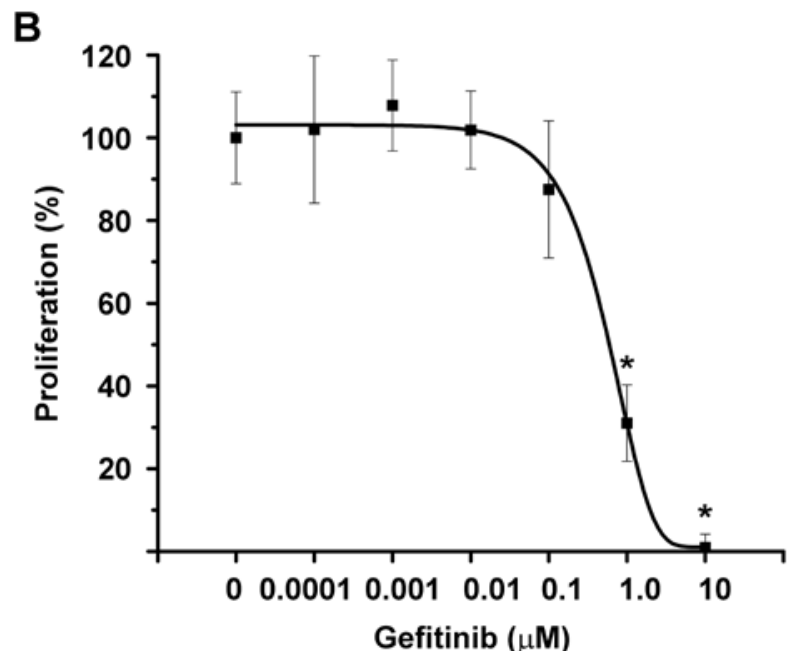

cells. Accordingly, the percentage of cells arrested in G0/G1 increased, while the $\mathrm{S}$ phase diminished in the combined treatment when compared to vehicle-treated cells. These observations are consistent with more cells exiting the cell cycle after being exposed to the combined treatment. The $\mathrm{S}$ phase was not modified.

\section{DISCUSSION}

Recently, the use of antihistamines for cancer therapy has gained interest due to their efficacy, safety, and low cost ${ }^{27}$. In this study, we tested the commonly prescribed antihistamine astemizole with the EGFR-blocker gefitinib, and we show for the first time that this combination had a synergistic effect on growth inhibition of cultured breast cancer cells. The synergistic interaction observed between these two compounds might be due to several mechanisms including the dual target of EAG1, both at the level of activity and expression, and the concomitant blocking of EGFR signaling. Indeed, the rationale to use astemizole and gefitinib in combination was based on preclinical data showing that TKIs abate the ability of EGFR to phosphorylate EAG1, while astemizole inhibits both EAG1 activity and expression, resulting in decreased cell proliferation and 
Figure 3. The combination of astemizole and gefitinib inhibited cell proliferation in a greater extent than each compound alone. The cells were incubated in the presence of astemizole and gefitinib alone or combined at their corresponding Inhibitory concentrations (IC) 20 and $I_{50}$ values. (A) cell proliferation was evaluated using XTT method. (B) cell density was measured by SRB assay. Results are depicted as the mean \pm standard deviation of sextuplicate determinations and represent at least five (A), and three different experiments (B). Data from vehicle treated cells (-) were set to $100 \%$ and the rest was normalized accordingly. ${ }^{*} p<0.05$ statistical significance versus vehicle, ${ }^{* *} p<0.05$ versus each compound alone and ${ }^{* * *} p<0.05$ versus astemizole.

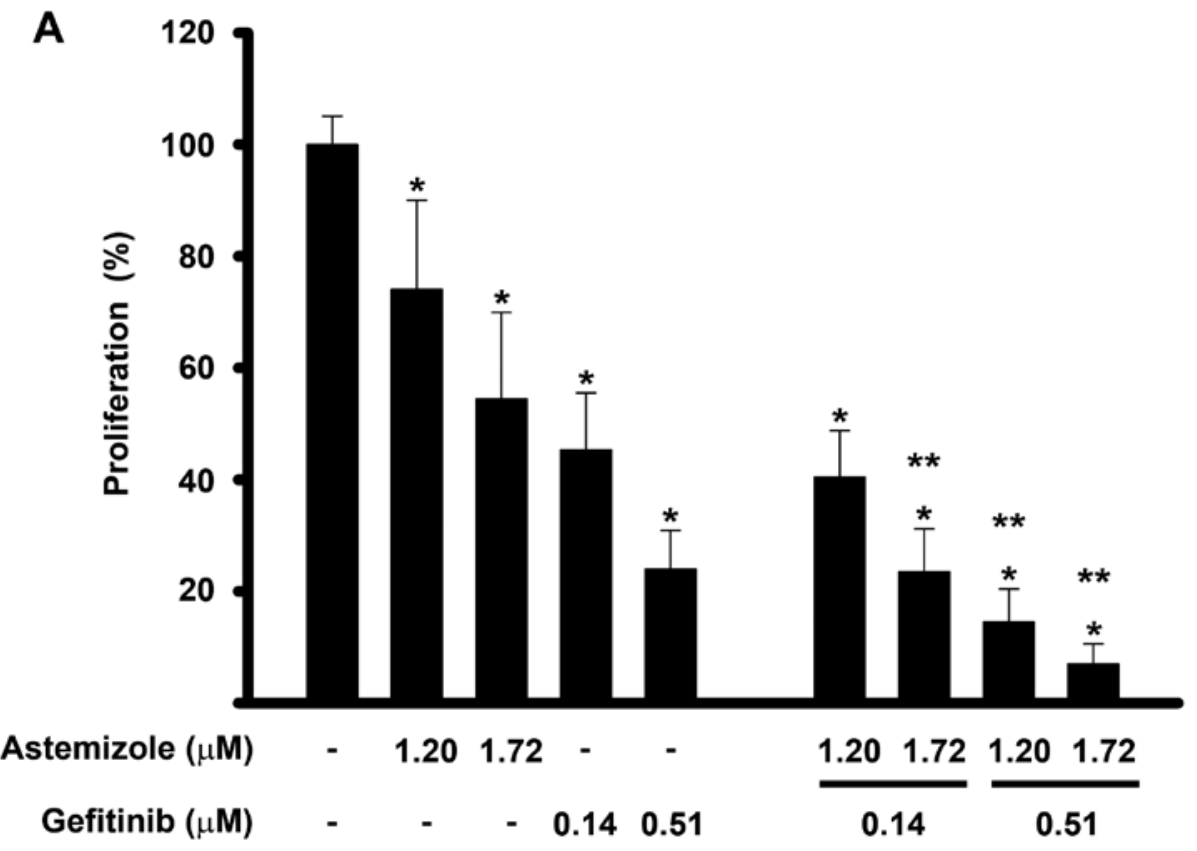

B

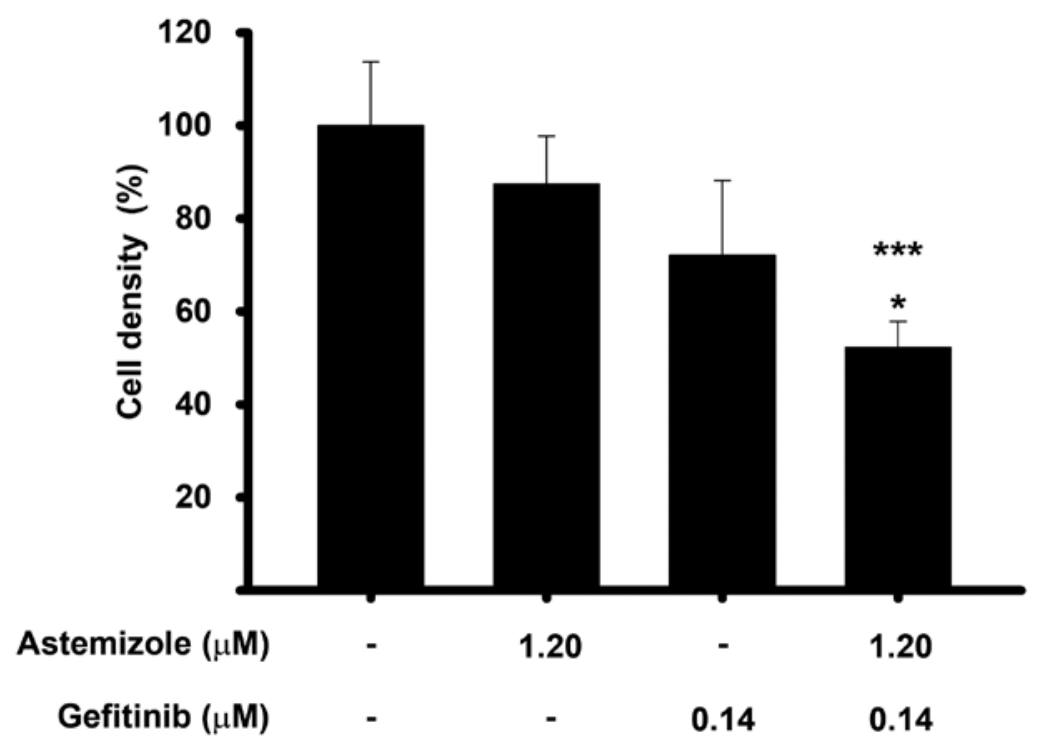

tumor progression ${ }^{16,19,20,29}$. The combination of gefitinib and astemizole has previously been tested in human lung cancer cell lines, showing, in a similar manner to our results, that the drug combination at their $I^{20}$ had a superior effect in reducing cell proliferation and survival while increased apoptosis in comparison to each compound alone ${ }^{32}$.

It is worth mentioning that some TKIs have been shown to inhibit members of the cytochrome P450 
family (CYPs), which should be considered when combining TKls with drugs that are CYPs substrates, due to the possibility of increased drug toxicity or reduced pharmacological effects ${ }^{33}$. In this regard, astemizole, used in this study, is catabolized by CYP3A4, a cytochrome that also plays a role in gefitinib metabolism. Previous reports demonstrated that gefitinib inhibits CYP3A4 activity in almost $20 \%{ }^{33}$; therefore, we hypothesize that lower concentrations of astemizole will result in a greater effect in vivo when combined with gefitinib, in a similar manner as seen in this in vitro study.

Of note, herein, we showed that the calculated $\mathrm{IC}_{20}$ and $I C_{50}$ of gefitinib in BT-474 cells are in the range of clinically achievable concentrations. As a reference, the steady-state plasma concentrations of gefitinib observed in cancer patients receiving 225-300 mg/ day of TKI ranged between $0.35 \mu \mathrm{M}$ and $0.53 \mu \mathrm{M}$, with clinically meaningful disease stabilization in a range of different tumor types ${ }^{34,35}$. In our study, $I_{20}$ and $\mathrm{IC}_{50}$ values of gefitinib were 0.14 and $0.51 \mu \mathrm{M}$,
Figure 4. Combination index $(\mathrm{Cl})$ values and fraction affected from different schemes of drug combinations. The BT474 cells were co-incubated at the corresponding inhibitory concentrations $(\mathrm{IC}) \mathrm{IC}_{20}-\mathrm{IC} \mathrm{C}_{20}(\bullet), \mathrm{IC}_{50}-\mathrm{IC} \mathrm{C}_{20}(\boldsymbol{\nabla}), \mathrm{IC}_{20}-\mathrm{IC} \mathrm{C}_{50}(\mathrm{O})$ and $\mathrm{IC}_{50}-\mathrm{IC} \mathrm{C}_{50}(\triangle)$ values of astemizole and gefitinib, respectively. $\mathrm{Cl}$ value of 1 indicates additive effect (denoted by the horizontal line) and the values below this line mean synergistic effect. All the combination schemes showed synergism at different intensities.

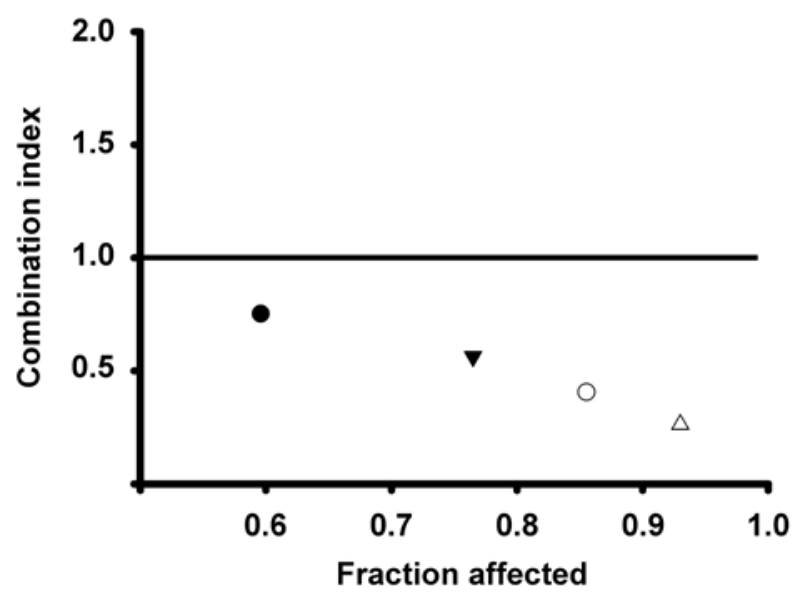

Figure 5. Effects of the astemizole-gefitinib combination on the cell cycle profile in breast cancer. Cells were incubated in the absence (-) or presence of their corresponding $I_{50}$ value of astemizole and gefitinib alone or in combination for $96 \mathrm{~h}$. The percentage of breast cancer cells in different phases of the cell cycle is shown. ${ }^{*} p<0.05$ versus untreated cells (t-test), ${ }^{* *} p=$ 0.002 versus untreated cells (one-way ANOVA). ${ }^{* * *} p=0.002$ versus astemizole-treated cells (one-way ANOVA). Bars represent data from at least three different experiments.

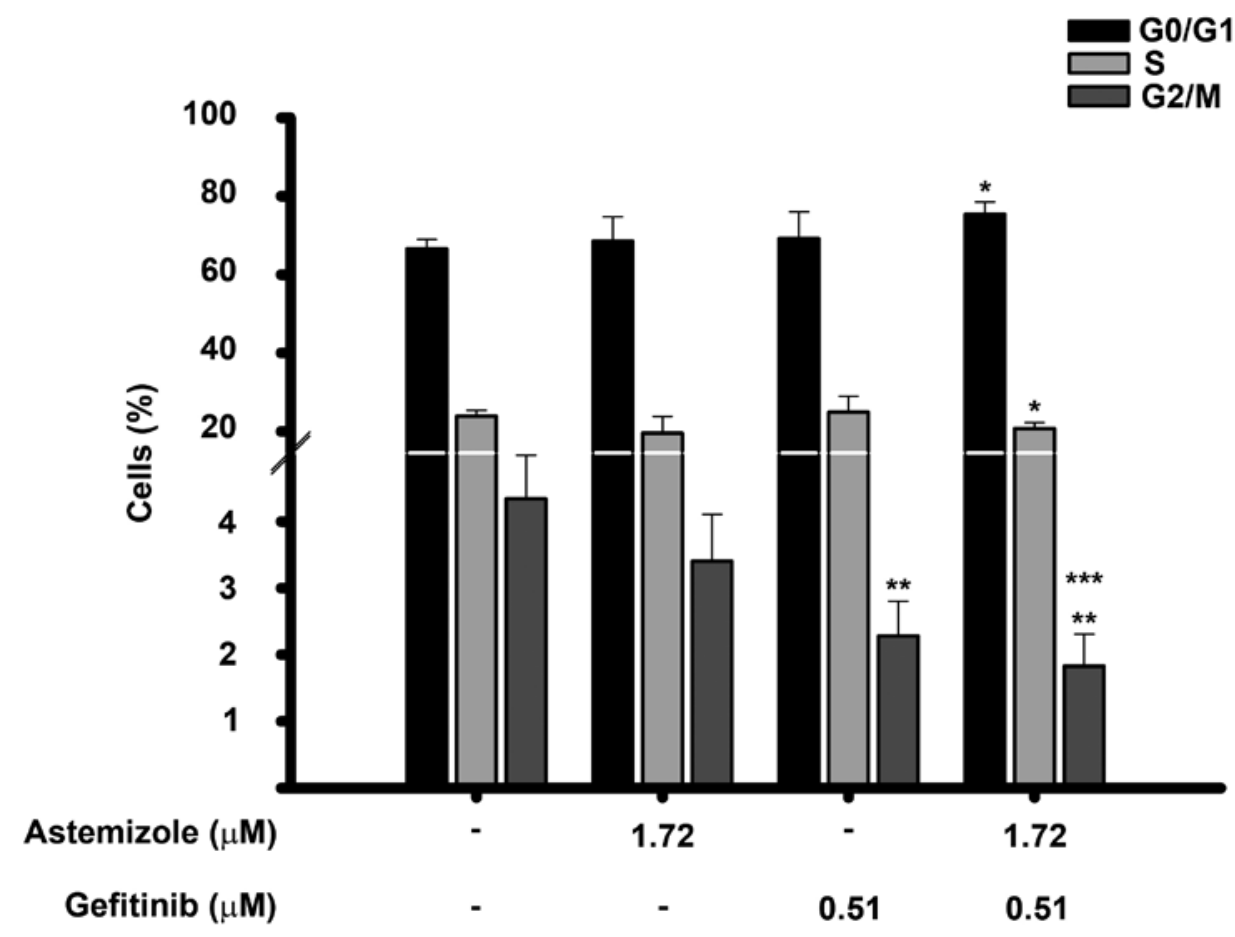


respectively. Therefore, it might be possible to lower the dose of gefitinib to patients by the concomitant administration with astemizole, which may result in benefit to reduce undesirable side effects of TKI.

In the case of astemizole, reported therapeutic and toxic serum levels are $0.05 \mu \mathrm{g} / \mathrm{mL}(0.10 \mu \mathrm{M})$ and 14 $\mu \mathrm{g} / \mathrm{mL}(30.5 \mu \mathrm{M})$, respectively ${ }^{36}$; therefore, the $\mathrm{IC}_{20}$ and $\mathrm{IC}_{50}$ values calculated in this study are higher than the therapeutic values but significantly lower than those associated with toxicity. Nevertheless, it should be noted that astemizole therapeutic levels have been calculated when prescribed as an antihistamine, not as an anticancer agent, which remains to be determined in future studies and are expected to be higher. In this regard, this study suggests that under in vivo conditions, astemizole might be used at lower doses when combined with gefitinib, due to the synergy that results from the interaction of these drugs and the gefitinib-dependent inhibition of CYP3A4.

Our results showing that the combination of gefitinib and astemizole synergistically inhibited cell proliferation while significantly reduced the $G 2 / M$ and increased the G0/G1 phases of the cell cycle, allow us to suggest that the combination of the drugs can modify the cell cycle profile in breast cancer cells favoring cell death. This assumption is supported by previous reports showing that astemizole and gefitinib alone can inhibit cyclin D1 and E expression and provoke cell cycle arrest in G0/G1 and/or cell death in breast cancer ${ }^{14,37}$. Given the strong dependence of EAG1 proliferative potential on EGFR expression and activity, we believe that the drug combination studied herein might be a good therapeutic option for patients bearing tumors coexpressing HER2/EGFR/ $E A G 1$, regardless of the presence of $E R$, and irrespective of the tumor dependence on estrogens to survive. Moreover, since EAG1 may also be upregulated by estrogens, as previously shown in cervical cancer cells $^{38}$, the combination of astemizole/gefitinib represents a good option to further abate estrogendependent EAG1-induced cell proliferation.

In summary, the results of the present study suggest that strategies involving the dual blockade of EAG1 may significantly improve the benefits of standard chemotherapy regimens, including tyrosine kinases inhibition, in patients affected with breast cancer.

\section{ACKNOWLEDGMENTS}

This study was funded by the Consejo Nacional de Ciencia y Tecnología (CONACyT, México) grant number 256994 to RG, and by the Instituto Científico Pfizer (grant INCMN/110/08/PI/86/15 to RGB). Mariana Segovia Martínez is grateful for the postdoctoral fellowship received from the Fundación para la Salud y la Educación Dr. Salvador Zubirán (Grant P-318).

\section{REFERENCES}

1. Jemal A, Bray F, Center MM, et al. Global cancer statistics. CA Cancer J Clin. 2011;61:69-90.

2. Reis-Filho JS, Tutt AN. Triple negative tumours: a critical review. Histopathology. 2008;52:108-18

3. Zhang $M$, Zhang $X$, Zhao S, et al. Prognostic value of survivin and EGFR protein expression in triple-negative breast cancer (TNBC) patients. Target Oncol. 2014;9:349-57.

4. Nicholson RI, Gee JM, Harper ME. EGFR and cancer prognosis. Eur J Cancer. 2001;37 Suppl 4:S9-15.

5. Yang $\mathrm{CH}, \mathrm{Yu}$ CJ, Shih JY, et al. Specific EGFR mutations predict treatment outcome of stage IIIB/IV patients with chemotherapy-naive non-small-cell lung cancer receiving first-line gefitinib monotherapy. J Clin Oncol. 2008;26:2745-53.

6. Moulder SL, Yakes FM, Muthuswamy SK, et al. Epidermal growth factor receptor (HER1) tyrosine kinase inhibitor ZD1839 (Iressa) inhibits HER2/neu (erbB2)-overexpressing breast cancer cells in vitro and in vivo. Cancer Res. 2001;61:8887-95.

7. Anido J, Matar P, Albanell J, et al. ZD1839, a specific epidermal growth factor receptor (EGFR) tyrosine kinase inhibitor, induces the formation of inactive EGFR/HER2 and EGFR/HER3 heterodimers and prevents heregulin signaling in HER2-overexpressing breast cancer cells. Clin Cancer Res. 2003;9:1274-83.

8. Campiglio M, Locatelli A, Olgiati C, et al. Inhibition of proliferation and induction of apoptosis in breast cancer cells by the epidermal growth factor receptor (EGFR) tyrosine kinase inhibitor ZD1839 ('iressa') is independent of EGFR expression level. J Cell Physiol. 2004;198:259-68.

9. Baselga J, Albanell J, Ruiz A, et al. Phase II and tumor pharmacodynamic study of gefitinib in patients with advanced breast cancer. J Clin Oncol. 2005;23:5323-33.

10. von Minckwitz G, Jonat W, Fasching P, et al. A multicentre phase II study on gefitinib in taxane-and anthracycline-pretreated metastatic breast cancer. Breast Cancer Res Treat. 2005;89:165-72.

11. Dickler MN, Cobleigh MA, Miller KD, Klein PM, Winer EP. Efficacy and safety of erlotinib in patients with locally advanced or metastatic breast cancer. Breast Cancer Res Treat. 2009; 115:115-21.

12. Bernsdorf $M$, Ingvar $C$, Jörgensen $L$, et al. Effect of adding gefitinib to neoadjuvant chemotherapy in estrogen receptor negative early breast cancer in a randomized phase II trial. Breast Cancer Res Treat. 2011;126:463-70.

13. Hopper-Borge EA, Nasto RE, Ratushny V, et al. Mechanisms of tumor resistance to EGFR-targeted therapies. Expert Opin Ther Targets. 2009;13:339-62.

14. Borowiec AS, Hague F, Gouilleux-Gruart V, Lassoued K, OuadidAhidouch $H$. Regulation of IGF-1-dependent cyclin D1 and E expression by hEag 1 channels in MCF-7 cells: the critical role of hEag1 channels in G1 phase progression. Biochim Biophys Acta. 2011;1813:723-30

15. Ouadid-Ahidouch H, Roudbaraki M, Delcourt P, et al. Functional and molecular identification of intermediate-conductance $\mathrm{ca}(2+)$-activated $\mathrm{K}(+)$ channels in breast cancer cells: association with cell cycle progression. Am J Physiol Cell Physiol. 2004;287:C125-34.

16. Ouadid-Ahidouch $H$, Le Bourhis $X$, Roudbaraki $M$, et al. Changes in the $\mathrm{K}+$ current-density of MCF- 7 cells during progression through the cell cycle: possible involvement of a h-ether.a-gogo K+ channel. Receptors Channels. 2001;7:345-56. 
17. Ouadid-Ahidouch $\mathrm{H}$, Chaussade $\mathrm{F}$, Roudbaraki $\mathrm{M}$, et al KV1.1 $K(+)$ channels identification in human breast carcinoma cells: involvement in cell proliferation. Biochem Biophys Res Commun. 2000;278:272-7.

18. Wonderlin WF, Strobl JS. Potassium channels, proliferation and G1 progression. J Membr Biol. 1996;154:91-107.

19. García-Becerra R, Díaz L, Camacho J, et al. Calcitriol inhibits etherà go-go potassium channel expression and cell proliferation in human breast cancer cells. Exp Cell Res. 2010;316:433-42.

20. García-Quiroz J, García-Becerra R, Barrera D, et al. Astemizole synergizes calcitriol antiproliferative activity by inhibiting $C Y$ P24A1 and upregulating VDR: a novel approach for breast cancer therapy. PLoS One. 2012;7:e45063.

21. García-Quiroz ], García-Becerra R, Santos-Martínez N et al. In vivo dual targeting of the oncogenic ether-à-go-go-1 potassium channel by calcitriol and astemizole results in enhanced antineoplastic effects in breast tumors. BMC Cancer. 2014;14:745

22. Ouadid-Ahidouch $H$, Ahidouch $A$. $K+$ channel expression in human breast cancer cells: involvement in cell cycle regulation and carcinogenesis. J Membr Biol. 2008;221:1-6.

23. Pardo LA, Stühmer W. Eag1: an emerging oncological target. Cancer Res. 2008;68:1611-3.

24. Camacho J. Ether à go-go potassium channels and cancer. Cancer Lett. 2006;233:1-9.

25. Hemmerlein B, Weseloh RM, Mello de Queiroz F, et al. Overexpression of eag 1 potassium channels in clinical tumours. Mol Cancer. 2006;5:41.

26. García-Quiroz ], Camacho J. Astemizole: an old anti-histamine as a new promising anti-cancer drug. Anticancer Agents Med Chem. 2011;11:307-14.

27. Ellegaard AM, Dehlendorff C, Vind AC, et al. Repurposing cationic amphiphilic antihistamines for cancer treatment. EBioMedicine. 2016;9:130-9.
28. García-Ferreiro RE, Kerschensteiner D, Major F, et al. Mechanism of block of hEag1 $\mathrm{K}+$ channels by imipramine and astemizole. J Gen Physiol. 2004;124:301-17.

29. Wu W, Dong $M Q, W u X G$, et al. Human ether-à-go-go gene potassium channels are regulated by EGFR tyrosine kinase. Biochim Biophys Acta. 2012;1823:282-9.

30. Vichai V, Kirtikara K. Sulforhodamine B colorimetric assay for cytotoxicity screening. Nat Protoc. 2006;1:1112-6.

31. Chou TC. Drug combination studies and their synergy quantification using the chou-talalay method. Cancer Res. 2010;70:440-6

32. Chávez-López MG, Zúñiga-García V, Hernández-Gallegos E, et al. The combination astemizole-gefitinib as a potential therapy for human lung cancer. Onco Targets Ther. 2017;10:5795-803.

33. Wang ZX, Sun J, Howell CE, et al. Prediction of the likelihood of drug interactions with kinase inhibitors based on in vitro and computational studies. Fundam Clin Pharmacol. 2014;28:551-82.

34. Baselga J, Rischin D, Ranson M, et al. Phase I safety, pharmacokinetic, and pharmacodynamic trial of ZD1839, a selective oral epidermal growth factor receptor tyrosine kinase inhibitor, in patients with five selected solid tumor types. J Clin Oncol. 2002:20:4292-302

35. Costa DB, Kobayashi S, Yeo WL, Hamada A. Serum concentrations of erlotinib at a dose of $25 \mathrm{mg}$ daily. J Thorac Oncol. 2010;5:1311-2.

36. Schulz M, Schmoldt A. Therapeutic and toxic blood concentrations of more than 800 drugs and other xenobiotics. Pharmazie. 2003;58:447-74.

37. Krol ], Francis RE, Albergaria A et al The transcription factor FOXO3a is a crucial cellular target of gefitinib (Iressa) in breast cancer cells. Mol Cancer Ther. 2007;6:3169-79.

38. Díaz L, Ceja-Ochoa I, Restrepo-Angulo I, et al. Estrogens and human papilloma virus oncogenes regulate human ether-à-go-go-1 potassium channel expression. Cancer Res. 2009;69:3300-7. 